\title{
The role of ligament tension and sensomotoric system in total knee arthroplasty
}

\author{
Roland Becker $^{1} \cdot$ Michael Tobias Hirschmann $^{2} \cdot$ Jon Karlsson $^{3}$
}

Published online: 27 May 2017

(C) European Society of Sports Traumatology, Knee Surgery, Arthroscopy (ESSKA) 2017

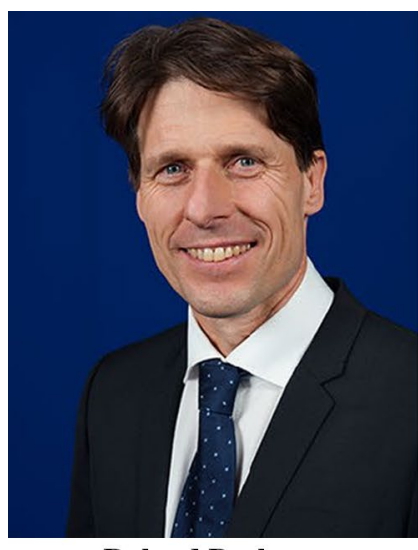

Roland Becker

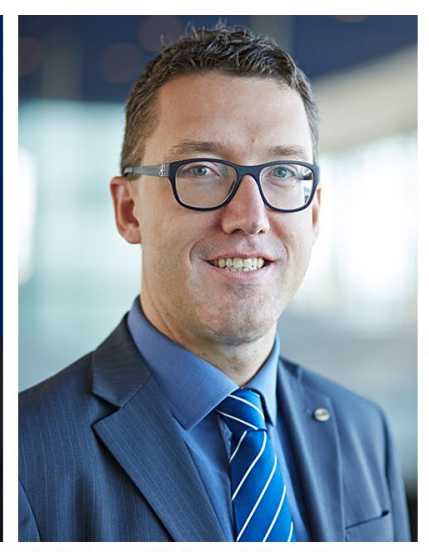

Michael Tobias Hirschmann

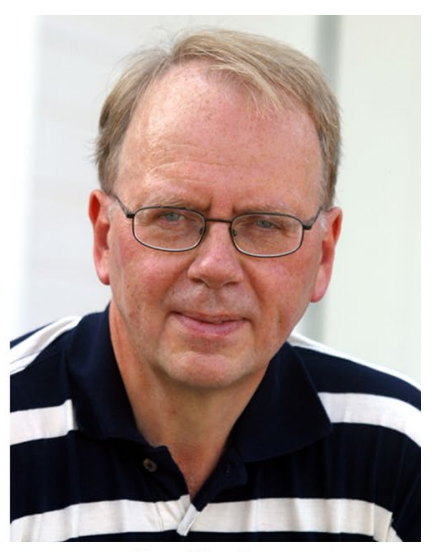

Jon Karlsson
Implant design, bony morphology and soft tissue balancing are the major issues in total knee arthroplasty (TKA). Looking at the implant design, it has not been changed significantly over the last four decades. Knee kinematic and soft tissue behaviour during motion is very complex and may show a significant impact in clinical outcome after TKA. Flexion and extension of the knee are guided by the

Roland Becker

roland_becker@yahoo.de

Michael Tobias Hirschmann

http://www.kneedoctor.ch/

1 Department of Orthopaedics and Traumatology, Hospital Brandenburg, Brandenburg Medical School "Theodor Fontane", Hochstrasse 26, 14776 Brandenburg, Germany

2 Department of Orthopaedic Surgery and Traumatology, Kantonsspital Baselland (Bruderholz, Liestal, Laufen), 4101 Bruderholz, Switzerland

3 Department of Orthopaedics, Sahlgrenska University, Hospital, Sahlgrenska Academy, Gothenburg, Sweden soft tissues. Menschik already reported in detail about the interplay between the cruciate and collateral ligaments [17]. The attachments of the cruciate and collateral ligaments follow circular paths, and there are minor changes in ligament tension only during flexion and extension.

A lot of research focuses on the improvement in knee function after TKA. The impact of proprioception and nociception on knee function after TKA is, however, not well understood. The knee is surrounded by a complex envelope of soft tissue, the site of the mechanoreceptors and nociceptors. Mechanoreceptors in the muscles, tendon and ligaments are responsible for the proprioception. The capsuloligamentous system is comprised of the joint capsule, medial and lateral collateral ligaments, anterior and posterior cruciate ligaments, popliteus tendon, hamstrings tendons and the menisci. Mechanoreceptors and nociceptors are embedded in the collagen of the ligaments and joint capsule transmitting neurosensory information to the spinal cord [10, 25]. Free nerve endings and Ruffini corpuscles are most frequently found in the knee [7]. Mechanoreceptors 
are identified close to the bone insertion. Free nerve endings and Golgi-like endings are predominantly identified in the PCL and Ruffini corpuscles in the popliteus tendon. Different articular sensory neurons innervate different tissues and may reflect different functions [9]. Proprioception is essential for joint protection, and it is known that proprioception is impaired in patients suffering osteoarthritis [2]. Many intraarticular structures contribute to the proprioception but are damaged during TKA.

This raises the question about the impact of the damage neurosensory system during TKA on final clinical outcome. How important is the sensorimotor system for good clinical function after TKA? There is some controversy in terms of the changes in joint position sense after TKA. While some researchers report a partial reversible effect of the neuromuscular deficits after total knee arthroplasty [5], others report the opposite and a further decrease in muscle strength and activation $[6,18,22,23]$. No correlation has been reported so far between proprioceptive acuity, pain and limitation in physical function in osteoarthritic knees [12]. In conclusion, poor proprioceptive activity does not appear to correlate with impaired knee function after TKA. For example, many mechanoreceptors are embedded in the posterior cruciate ligament, and one may presume that the preservation of the PCL will cause superior proprioceptive activity after TKA. A recent study compared CR and PS designs in total knee arthroplasty, and no differences in terms of proprioception and muscle strength were reported [24]. In contrast, preserving both of the ligaments during TKA, proprioception was similar to unicondylar knee arthroplasty as shown in another study (UKA) [3].

Tension of the soft tissue envelope of the knee shows direct impact on knee function after TKA. Inappropriate soft tissue tension may cause increased laxity from the biomechanical point of view, which will lead to knee instability and poor function. Knee instability after TKA is the cause of revision surgery in up to $25 \%$ and knee stiffness in $10-15 \%[8,16,21]$. The impact of changes in soft tissue tension pattern of the knee during motion is not well understood. Different strain behaviours have been reported between the medial and lateral collateral ligaments during knee motion [13]. Preservation of the correct soft tissue tension during TKA is very demanding. Moreover, the impact on soft tissue laxity or tension on the neurosensory system is not well understood. Increase in soft tissue tension will alter the stiffness of the soft tissue complex and may lead to pain [14]. Increase in tension of the soft tissue complex has shown alteration in voluntary quadriceps muscle activation and changes in muscle strength and gait [19]. It has been shown that pain predominantly occurs at the medial and lateral retinaculum and might be the cause for increase in pain, when the implantation of a total joint causes tightness of the soft tissue structures [11]. The stiffness of the soft tissue complex in osteoarthritic knees was studied in extension and flexion [1]. The stiffness in extension and flexion was 8.9 and $8.5 \mathrm{~N} / \mathrm{mm}$, respectively, with a soft tissue tension of $60 \mathrm{~N}$ and increased to 26.6 and $21.4 \mathrm{~N} / \mathrm{mm}$ with a tension of $180 \mathrm{~N}$. The authors concluded that soft tissue tension during surgery of 80-160 N appears to be appropriate from the clinical point of view as it does not affect post-operative range of motion. That study also shows that the stiffness of the tissue differs in extension and flexion [1]. Manual stress testing, spacer blocks, tensiometers and navigation are all used in TKA to preserve static and dynamic soft tissue constraints.

In one of the studies of the current issue of the journal, the accurate soft tissue balance was investigated in human cadavers and showed an inverse relationship of laxity and contact force [15]. However, coronal and rotational laxity changes after TKA when compared with the native knee laxity. Laxity in transverse and frontal plane increased significantly upon increased knee flexion [15]. These findings are supported by other studies. Unequal laxity at $0^{\circ}, 45^{\circ}$, $90^{\circ}$ of knee flexion has been reported [20]. Significantly greater laxity in varus and valgus and internal and external rotation has been reported upon increased flexion.

Even when TKA surgery is performed very precisely, differences in kinematics and soft tissue restraints occur. The usage of a tensiometer is helpful to adjust the distraction force when creating the extension and flexion gap during arthroplasty surgery [4].

There is still a significant lack of knowledge in the understanding of the neuromuscular function of the knee and effect of different tension patterns of the soft tissue on the outcome after TKA. Many studies have focused on correct balancing of the knee during TKA, but a balanced knee also can end up in poor function due to significantly abnormal soft tissue tension.

\section{References}

1. Asano H, Muneta T, Hoshino A (2008) Stiffness of soft tissue complex in total knee arthroplasty. Knee Surg Sports Traumatol Arthrose 16:51-55

2. Barrett D, Cobb A, Bentley G (1991) Joint proprioception in normal, osteoarthritic and replaced knees. J Bone Joint Surg (Br) 73-B:53-56

3. Baumann F, Bahadin Ö, Krutsch W, Zellner J, Nerlich M, Angele P, Tibesku CO (2016) Proprioception after bicruciate-retaining total knee arthroplasty is comparable to unicompartmental knee arthroplasty. Knee Surg Sports Traumatol Arthrosc. doi:10.1007/ s00132-016-3239-8

4. Becker R, Paech C, Denecke A (2017) Fixed bearing unicondylar arthroplasty in medial osteoarthritis of the knee. Oper Orthop Traumatol 29(1):4-16

5. Berth A, Urbach D, Awiszus F (2002) Improvement of voluntary quadriceps muscle activation after total knee arthroplasty. Arch Phys Med Rehabil 83:1432-1436 
6. Chang AH, Lee SJ, Zhao H, Ren Y, Zhang LQ (2014) Impaired varus-valgus proprioception and neuromuscular stabilization in medial knee osteoarthritis. J Biomech 47:360-366

7. Çabuk H, Kuşku Çabuk F (2016) Mechanoreceptors of the ligaments and tendons around the knee. Clin Anat 29:789-795

8. Dalury DF, Pomeroy DL, Gorab RS, Adams MJ (2013) Why are total knee arthroplasties being revised? J Arthroplasty 28:120-121

9. da Silva Serra I, Husson Z, Bartlett JD, Smith ES (2016) Characterization of cutaneous and articular sensory neurons. Mol Pain 12:1-14

10. Del Valle ME, Harwin SF, Maestro A, Murcia A, Vega JA (1998) Immunohistochemical analysis of mechanoreceptors in the human posterior cruciate ligament: a demonstration of its proprioceptive role and clinical relevance. J Arthroplasty 13:916-922

11. Dye SF, Vaupel GL, Dye CC (1998) Conscious neurosensory mapping of the internal structures of the human knee without intraarticular anesthesia. Am J Sports Med 26:773-777

12. Felson DT, Gross KD, Nevitt MC, Yang M, Lane NE, Torner JC, Lewis CE, Hurley MV (2009) The effects of impaired joint position sense on the development and progression of pain and structural damage in knee osteoarthritis. Arthritis Rheum 61:1070-1076

13. Jeffcote B, Nicholls R, Schirm A, Kuster M (2006) The variation in medial and lateral collateral ligament strain and tibiofemoral forces following changes in the flexion and extension gaps in total knee replacement. J Bone Joint Surg (Br) 89-B:1528-1533

14. Lu Y, Chen C, Kallakuri S, Patwardhan A, Cavanaugh JM (2005) Neurophysiological and biomechanical characterization of goat cervical facet joint capsules. J Orthop Res 23:779-787

15. Manning WA, Ghosh K, Blain A, Longstaff L, Deehan DJ (2016) Tibiofemoral forces for the native and post-arthroplasty knee: relationship to maximal laxity through a functional arc of motion. Knee Surg Sports Traumatol Arthrosc. doi:10.1007/ s00167-016-4093-2

16. McNabb CD, Kim RH, Springer RH (2015) Instability after Total Knee Arthroplasty. J Knee Surg 28:97-104
17. Menschik A (1974) Mechanik des Kniegelenkes Teil 1. Z Orthop 112:481-495

18. Mizner RL, Stevens JE, Snyder-Mackler L (2003) Voluntary activation and decreased force production of the quadriceps femoris muscle after total knee arthroplasty. Phys Ther 83:359-365

19. Pietrosimone B, Lepley AS, Murray AM, Thomas AC, Bahhur NO, Schwartz TA (2014) Changes in voluntary quadriceps activation predict changes in muscle strength and gait biomechanics following knee joint effusion. Clin Biomech (Bristol, Avon) 29:923-929

20. Roth JD, Howell SM, Hull ML (2015) Native knee laxities at $0^{\circ}, 45^{\circ}$, and $90^{\circ}$ of flexion and their relationship to the goal of the gap-balancing alignment method of total knee arthroplasty. J Bone Joint Surg Am 97:1678-1684

21. Singh J, Politis A, Loucks L, Hedden DR, Bohm ER (2016) Trends in revision hip and knee arthroplasty observations after implementation of a regional joint replacement registry. Can Surg 59:304-310

22. Stevens JE, Mizner RL, Snyder-Mackler L (2003) Quadriceps strength and volitional activation before and after total knee arthroplasty for osteoarthritis. J Orthop Res 21:775-779

23. Vahtrik D, Gapeyeva H, Aibast H, Ereline J, Kums T, Haviko T, Märtson A, Schneider G, Pääsuke M (2012) Quadriceps femoris muscle function prior and after total knee arthroplasty in women with knee osteoarthritis. Knee Surg Sports Traumatol Arthrosc 20:2017-2025

24. Vandekerckhove PJ, Parys R, Tampere T, Linden P, Van den Daelen L, Verdonk PC (2014) Does cruciate retention primary total knee arthroplasty affect proprioception, strength and clinical outcome? Knee Surg Sports Traumatol Arthrosc 23:1644-1652

25. Zimny ML, Schutte M, Dabezies E (1986) Mechanoreceptors in the human anterior cruciate ligament. Anat Rec 214:204-209 